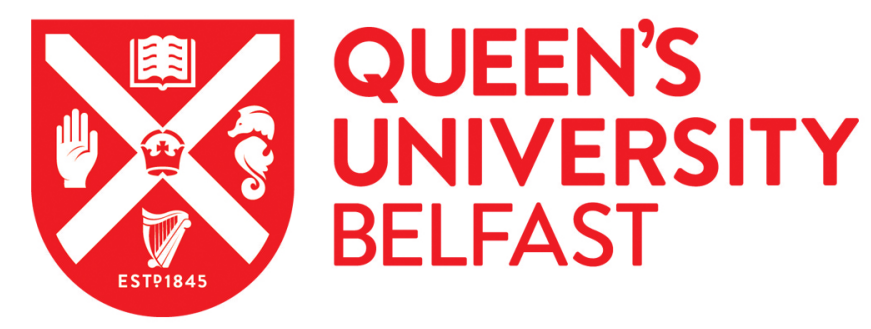

\title{
Field-Scale Heterogeneity and Geochemical Regulation of Arsenic, Iron, Lead, and Sulphur Bioavailability in Paddy Soil
}

Fang, W., Williams, P., Fang, X., Amoah-Antwi , C., Yin, D., Li, G., Ma, L., \& Luo, J. (2018). Field-Scale Heterogeneity and Geochemical Regulation of Arsenic, Iron, Lead, and Sulphur Bioavailability in Paddy Soil. Environmental Science and Technology, 1-37. https://doi.org/10.1021/acs.est.8b01947

Published in:

Environmental Science and Technology

Document Version:

Peer reviewed version

Queen's University Belfast - Research Portal:

Link to publication record in Queen's University Belfast Research Portal

\footnotetext{
General rights

Copyright for the publications made accessible via the Queen's University Belfast Research Portal is retained by the author(s) and / or other copyright owners and it is a condition of accessing these publications that users recognise and abide by the legal requirements associated with these rights.
}

Take down policy

The Research Portal is Queen's institutional repository that provides access to Queen's research output. Every effort has been made to ensure that content in the Research Portal does not infringe any person's rights, or applicable UK laws. If you discover content in the Research Portal that you believe breaches copyright or violates any law, please contact openaccess@qub.ac.uk. 

9 0 6

\section{Field-Scale Heterogeneity and Geochemical Regulation of} Arsenic, Iron, Lead, and Sulphur Bioavailability in Paddy

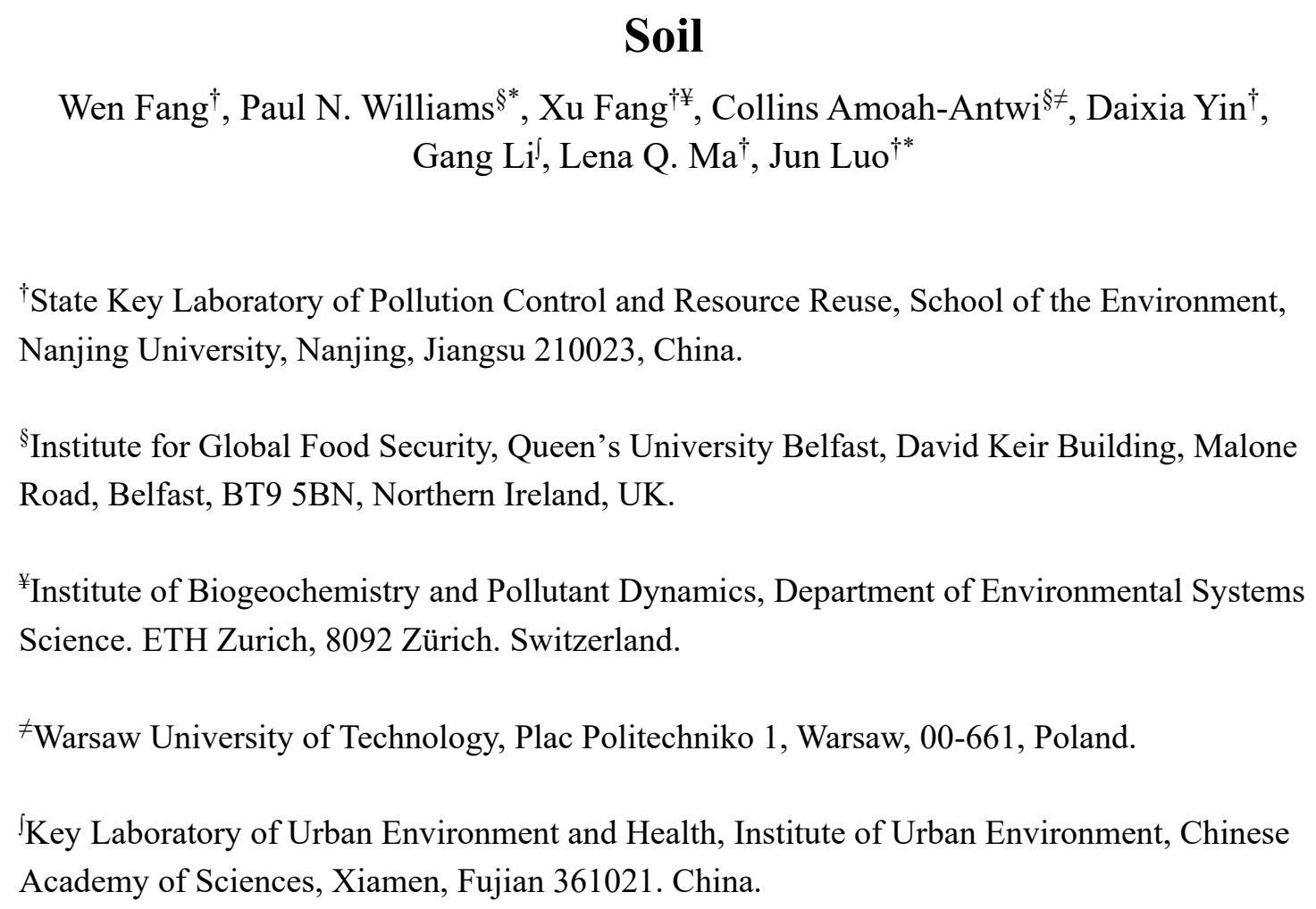
31 2 3 4 35 


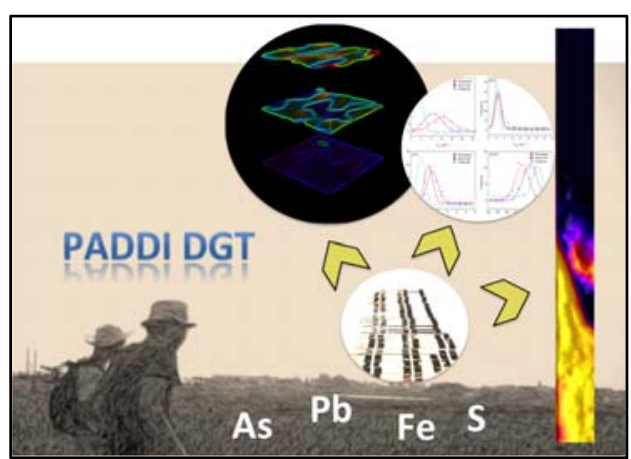
concentrations across the field were approximately uniform (R.S.D. $<10 \%$ ), but bioavailability was shown to vary significantly as determined from 864 microgel measurements housed within 72 PADDI arrays. Porewater As measurements were unable to differentiate the top/rhizosphere and bulk/deeper-soil layers. However, dynamic sampling with DGT revealed significant differences. Heterogeneity

55 behaviors varied greatly between the different elements. Arsenic bioavailability was 56 stable laterally across the field, but varied with depth, which was in contrast to the 
trends for $\mathrm{Pb} . \mathrm{Fe} / \mathrm{S}^{(-\mathrm{II})}$ change was bi-directional, differing horizontally and vertically throughout the field. The heterogeneity in $\mathrm{Pb}$ bioavailability due the high frequency of hotspot maxima, which were discretely dispersed across the paddy proved the most difficult to simulate, requiring the greatest number of probe deployments to determine a reliable field-average. The DGT-PADDI system provides a new characterization of infield trends for improved trace-inorganics' management in agricultural wetlands.

\section{- INTRODUCTION}

Energy production processes, manufacturing, mining, irrigation, fertilizers use, and wastes discharges have caused a widespread redistribution of trace inorganic pollutants, such as arsenic $(\mathrm{As})$, cadmium $(\mathrm{Cd})$ and lead $(\mathrm{Pb})$, resulting in an extensive global patchwork of localized environmental enrichments. ${ }^{1-4}$ Due to a combination of rice physiology and the chemical settings that develop when paddy fields are flooded, even soils moderately elevated in these toxic metals/metalloids can still produce grain of unacceptable/inferior quality. ${ }^{5}$ However, detecting this marginal land and making it safe for rice production is challenging because element bioavailability at the field-scale is difficult to determine ${ }^{6,7}$. This is due to the spatial heterogeneity in element release, coupled with a highly dynamic kinetic regulation of bioavailability caused by the fluctuating redox environments created when wetlands are managed as high-intensity agricultural systems ${ }^{6,8}$ (Figure 1A).

Most rice is cultivated at high densities in a semi-aquatic environment. Unlike most natural wetlands, there is a regular bi- or tri-annual mixing of the field's topsoil, 
commonly down to a depth of $\sim 20 \mathrm{~cm}$, which homogenizes the soil before rice is planted. However, during periods of flooding, layered redox zones develop in rice paddies, starting at the soil-water interface (SWI), ending with the plough pan (Figure 1A). These banded reaction phases determine the general (bio)chemical conditions in the soil, and therefore control the extent and intensity of element release. However, the supply of soil derived trace inorganics, the pool available for plant uptake, is influenced by numerous reaction step couplings, including dissolution/precipitation, adsorption/desorption, and oxidation/reduction processes. There is also an interplay among various elemental species which can influence soil-porewater partitioning as well as the absorption of species into cellular material. ${ }^{9}$ All these reactions are further modulated by plant-soil and microbial process-soil interactions (Figure 1A). ${ }^{10}$ For example, the spatial heterogeneity of labile organics from sources (such as root exudates, rhizodeposits, and the decomposition of plant material) creates both microand macro-site hotspots (Figure 1). The microbiome activity in these hotspots can be 2-20 times higher than in bulk soil environs, ${ }^{11}$ bestowing primary fixation control on trace inorganics in soils. Finally, differences in soil porosity and particle size with depth and field locality mean there is diversity in porewater-soil equilibrium states, a catalyst propagating further abiotic and biotic process heterogeneity.

When predicting plant uptake of trace inorganics in rice, only limited gains can be made if the resolution of soil sampling is insufficient to cope with the variation within the field-site or ex-situ testing regimes are employed. However, topsoil collection, followed by chemical extraction testing in the laboratory forms the basis of 
most traditional and current soil safety screening programmes. ${ }^{12}$ In-situ passive sampling of trace inorganic fluxes is a superior measure of true elemental bioavailability. It provides a time-integrated quantification and low-disturbance sampling of the soil environment. The "time lapse photograph in a single frame" of solute dynamics captured by the samplers also encompasses not just the chemical processes governing element release but is a summation of all the biological and physical processes as well (Figure 1B). One of the most widely adopted passive sampling technologies is the diffusive gradients in-thin-films (DGT) technique. ${ }^{13}$ DGT has found favour in soil applications, not just due to its ease of use but because of its ability to successfully mimic plant uptake processes in a wide range of scenarios ${ }^{14-18}$. Although, not so well-defined, there is also emerging lines of evidence that suggest that the DGT measurement is also representative of bioavailability to a wide range of other biological receptors, including sediment fauna ${ }^{19}$ and microorganisms 20.

Two opportunities exist to modify currently DGT sampling approaches in rice paddies. The rice paddy/field 3D environment encompasses $>1000 \mathrm{~m}^{3}$, whereas the localized solute capture of standard DGT probes is $\sim 6 \mathrm{~cm}^{3}$. The placement of high resolution $(<1 \mathrm{~mm}) /$ ion mapping samplers in sufficient numbers to get good spatial coverage of typical paddy sites is a challenge, made more so, by the high prevalence of macro-niches, along with active roots within the rice soils (Figure 1). Although, potentially of general scientific interest, locating a sampler directly on an iron plaque encrusted root for example might not represent the processes or bioavailability 
occurring at the fieldscale. Here, adopting a high intensity micro-sampling approach provides the sampling frequency to unpick what is the common bioavailability, while simultaneously also detecting maxima and minima fluxes, and relating these back to specific zones. Yet, the analysis of micro-DGT samplers, has traditionally been hampered by their being less control over measurement uncertainties, when scaling down from the standard procedures, with the elution stage $\left(f_{\mathrm{e}}\right)$ contributing most significantly to this analysis error. ${ }^{21}$

Elution of the target analytes is necessary for solution mode analysis of DGT samplers, but other options exist in the form of solid-state analysis approaches, such as LA-ICPMS. The drive to better understand the cycling of trace inorganics by targeting the small-scale processes at the interface between different environmental compartments, has led to the rapid evolution of the sampling technologies for ion mapping of porewater solutes using $2 \mathrm{D} \mathrm{DGT}^{13,22-24}$. Rather fortuitously, this has also been benefited by major improvements to LA-ICPMS technologies, with new generation/commercially available mass-spectrometry systems providing greater sensitivities $\left({ }^{115} \mathrm{In} \mathrm{kcps} / \mathrm{ppb}>400\right)$ and signal stabilities (run times $>24 \mathrm{hrs}$ ). Couple this with an extension of the run times of gel analyses, due to recent developments in the sizes of ablation chambers, enabling DGT gel areas $>200 \mathrm{~cm}^{2}$ to be processed in one sitting, without having to break vacuum seals and replace the samples, ${ }^{13}$ then new possibilities for high-throughput and automated analysis are created.

In this study, a novel multiplexed micro-gel based DGT sampling probe (PADDI) was developed for field-scale in-situ measurement of bioavailability. The 
accumulation of target elements in micro-gels were measured with an optimized multi-elemental/high-throughput LA-ICPMS method for sensitive and rapid quantification. The DGT array configuration, comprising of different binders enabled the simultaneous measurement of cation and anion fluxes, providing a means to determine the spatial heterogeneity and geochemical regulation patterns within a field site area. The micro-gel deployment, involved 864 individual samplers, housed within 72 PADDI arrays. Heterogeneity, was assessed based on two principle criteria: firstly, the behavioral characteristics of bioavailability fluxes and secondly simulations of the sampling deployment intensity required to derive the overall field average. This evaluation not only provides insight into the mechanisms, interactions and nature of element bioavailability, but delivers important guidance for optimising future sampling strategies (i.e. distribution and location) for nutrient and pollutant risk assessment at the field scale.

\section{- EXPERIMENTAL SECTION}

\section{Design of the Paddy Adapted DGT Device for In-situ Bioavailability} Measurement (PADDI). Acrylonitrile butadiene styrene (ABS) (Engineering Workshop, Queen's University Belfast, UK) was used to construct the probes, based on adapted dimensions from the standard DGT Research ${ }^{\circledR}$ sediment housing (R-SP). ${ }^{25}$, ${ }^{26}$ The probe contained two identical faces/sampling planes, each with three micro-gel arrays, spaced $10 \mathrm{~cm}$ apart from each other (Figure 2). Each array comprized of four circular recesses each with a diameter of $5 \mathrm{~mm}$ and depth of $1 \mathrm{~mm}$, based on the 
validated miniaturized-DGT gel method of Alexa et al. ${ }^{25}$. This configuration enabled 24 gel combinations to be deployed in one PADDI probe.

We used four different kinds of DGT/DET gel combinations in one PADDI probe in this study for simultaneous measurement of $\mathrm{As}, \mathrm{Pb}, \mathrm{Fe}$, and $\mathrm{S}^{(-\mathrm{II})}$ fluxes and pore-water concentrations (Figure 2). The two toxic trace inorganics, As and $\mathrm{Pb}$ were selected since each pose serious growth/quality issues in rice cultivation, as well as being representative of both cation and oxyanion mobilization trends more generally. Arsenic species were not specifically measured, but the dominant form in flooded rice soils has been has been repeatedly shown to be $\mathrm{As}^{(\mathrm{III})} 27$, and a sub-aim of the work was to validate the measurement of total As with simultaneous deployment of two As-binding gels. Fe and $\mathrm{S}^{(-\mathrm{II})}$ measurements were included, as dual indicators of both the relative redox conditions of the soil zones, and also because their mobility patterns are strong determining factors for $\mathrm{As}$ and $\mathrm{Pb}$ release. ${ }^{27-29}$

Precipitated ferrihydrite gel $(\mathrm{PF})^{30}$ and precipitated zirconium oxide gel (PZ) ${ }^{16}$ were prepared to measure As fluxes. We used two kinds of gels to verify the As flux measurement since some studies suggest a disparity in the DGT measurement of As captured by DGT's with different binding gel configurations. ${ }^{31}$ SPR-IDA gel ${ }^{32}$ coupled with $\mathrm{AgI} \mathrm{gel}^{33}$ as the diffusive layer was provided by DGT Research Limited (Lancaster, UK) to measure Fe and $\mathrm{Pb}$ fluxes. DET gel ${ }^{34}$, bisacrylamide based gel was prepared to determine pore-water concentrations.

The assembly of acid-washed probes was performed in a laminar-flow clean bench/hood (class 100) (SW-CJ-1B-900, Wanda Technologies Co Ltd., Suzhou), 
located within in an ultra-clean laboratory (class 10,000). Each recess was filled with a double-layered gel combination, with the $0.8 \mathrm{~mm}$ diffusive gel overlaying the 0.4 mm binding gel (DGT) or DET gel. Next, the micro-gel arrays were overlaid by a well-fitting rectangular filter membrane (Pall Co. USA, $0.45 \mu \mathrm{m}$ pore size and 0.14 mm thickness). Edges of filter membranes were firmly secured to the probe with vinyl electrical tape (Scotch Super 33+) to seal the gels into the probes. ${ }^{8}$

Field Deployment of PADDI Probe. In-situ deployment of the PADDI probe was carried out in an uncontaminated paddy field with an area of about $2500 \mathrm{~m}^{2}$ in Jiangning District, Nanjing, China in late July, 2016. The field was spatially divided into 9 subsampling sites, $\sim 300 \mathrm{~m}^{2}$ (Figure 2) based on a square gridded pattern, with each site taking four PADDI probes to form a 8-sided sampling structure. The probes were gently pushed into the paddy soil, so that the uppermost array of gels were within $0-5 \mathrm{~cm}$ below the soil-water interface (SWI). Each probe set was located $\sim 10 \mathrm{~cm}$ from the center of the rice plants, and the distance between the rows of rice was $\sim 20 \mathrm{~cm}$. Calibrated temperature loggers (Maxim, DS1922L) were additionally placed in the soil, close to the middle array of gels. The probes with their respective temperature loggers were retrieved from the sites $24 \mathrm{hrs}$ after the deployment. Both probes and temperature loggers were immediately jet-washed with Milli-Q (MQ) water and wiped clean with laboratory-grade tissue paper prior to being placed in zip-lock clean bags for transfer back to the laboratory for disassembling. Based on the design of the PADDI probe, the bioavailability of target elements were determined at 
211 three depths, representing different soil zonations (rhizosphere: $0-5 \mathrm{~cm}$, anoxic bulk:

212 10-15 cm, and plough pan: 20-25 cm). Here, the definition of the rhizosphere was not

213 restricted solely to soils within the sub-mm range of the buried roots, but instead

214 encompassed a soil zone $0-5 \mathrm{~cm}$ below the SWI, which extended $10 \mathrm{~cm}$ out from the 215 center point of individual rice plants. and sample gels from PADDI probes, for LA-ICPMS analysis was carried out according to Gao and Lehto ${ }^{35}$. DGT/DET gels were placed on an acid-washed 0.45 $\mu \mathrm{m}$ cellulose nitrate filter with a backing layer of laboratory-grade tissue paper. Gels underwent initial air drying overnight, followed by complete desiccation in a gel dryer (Model 583, Biorad, Hercules, CA) at $60^{\circ} \mathrm{C}$ for 8 hrs prior to LA-ICPMS analysis. ${ }^{8,23}$ The accumulation of target elements within DET gels was semi-quantitatively determined by comparing the relative contents of elements between different PADDI probes. solid-state laser ablation system (UP-213, New Wave Research, Fremont, CA), then set-up first with primary calibrations using the National Institute of Standards and

231 Technology (NIST) glass standard 610. The LA-ICPMS system was optimized principally by adjusting gas flow rates, torch sampling depth, and radio frequency (RF) 
power to achieve the maximum signal intensity and stability of target elements while minimizing interferences. ${ }^{8}$ The instrumental parameters for analysis are listed in Table S1.

To obtain a good representative measurement of each miniaturized gel, a raster pattern, comprising of several lines with a total length of $10 \mathrm{~mm}$, encompassing a total area of $1 \mathrm{~mm}^{2}$ was applied to the samples and calibration gels. The center of each gel was targeted for the placement of the raster scan, to avoid measurement biases and edge effects associated with the outer gel exteriors. ${ }^{36}$ A series of standards for each gel matrix (SPR-IDA, FeOH, and $\mathrm{ZrO}$ ) were analyzed prior to the ablation of the samples and at the end of each analysis run.

The data processing method for LA-ICPMS is shown in Figure S2. Sensitivity drift during LA-ICPMS analysis can be caused by matrix differences, defocusing, and the deposition of analyzed materials. It will significantly influence the accuracy and precision of the results. To compensate for the possible deviation in laser focusing and aerosol transport efficiency during analysis an internal standard $(\mathrm{C}, \mathrm{m} / \mathrm{z} 13)$ was used. ${ }^{8}$, ${ }^{35}$ Furthermore, although rare in properly cleaned systems, each of the element signals needs to be filtered carefully for signal spikes, arising from either electronic, or systemic contamination (particles from a previous sample). ${ }^{37}$ Here, a common filtering approach by rejecting extreme values (Q1: first quartile, Q3: the third quartile, IQR: quartile difference: $>$ Q3+1.5IQR or $<$ Q1-1.5IQR) as outliers was applied. After filtering, each sample measurement comprized of $\sim 100$ discrete measurements (ablation spots). The normalized metal count rate was calculated at a spatial resolution 
of $100-200 \mu \mathrm{m}$.

256 For gel standards, the final intensity of the target element was determined from the averaged normalized intensity of more than 100 replicate measurements across a single gel. For sample gel analysis, the median was used instead of mean averages for the final intensity average. Laser ablation results obtained on blank resin gels allowed us to calculate the limits of detection (LODs) for each of the trace inorganics. The deviation..$^{24,35}$ concentrations ( $\left.\mathrm{C}_{\mathrm{DGT}}\right)$ of $\mathrm{As}, \mathrm{Pb}$, and Fe were calculated using Eq. 1.

$$
\mathrm{C}_{\mathrm{DGT}}=\frac{M \times \Delta g}{D \times t}
$$

Where $\mathrm{M}\left(\mathrm{ng} \mathrm{cm}{ }^{-2}\right)$ refers to the mass accumulation density of elements on DGT binding gels and is obtained through calibration standards in Figure S3. $\Delta \mathrm{g}$ is the the diffusion coefficient of target elements $(\mathrm{As}, \mathrm{Pb}$, and $\mathrm{Fe}$ ) through the diffusive gel.

Computer Imaging Densitometry (CID) Analysis of AgI Gel. AgI gels were analyzed by a computer-imaging densitometry method for measurement of dissolved $\mathrm{S}^{(-\mathrm{II})}{ }^{38}$ To remove color interferences from oxidized iron compounds, the AgI gels were soaked in a $0.01 \mathrm{M}$ solution of hydroxylamine hydrochloride for $12 \mathrm{hrs}$ before 
digital copies of the gels were recorded by a desktop scanner (Laserjet 1536dnf MFP, HP) at 1200 ppi. $^{38}$ The resulting JPEG images were converted to grey-scale using ImageJ software, with more intense gray-scale values indicating a higher labile concentration of $\mathrm{S}^{(-\mathrm{II})}$.

\section{Statistical Analysis. Normality of the measurements and homogeneity of variance} were tested using Shapiro-Wilk's W test and Levene's test. The influence of sampling sites and vertical zones on $C_{\text {DGT }}$ of $\mathrm{As}, \mathrm{Pb}, \mathrm{Fe}$, and gray-scale values of $\mathrm{S}^{(-\mathrm{II})}$ were performed using general linear modeling (GLM) and conducted using Minitab.

\section{- RESULTS AND DISCUSSION}

Method and Analysis Evaluation. DGT/LA-ICPMS. The validation of standards involves a two-step process, whereby replicates of each standard concentration are eluted and cross-checked against known solution concentrations used in the dosing of the samplers, which are further quality assured against certified reference material (CRM). Calibrations of $\mathrm{As}, \mathrm{Pb}$, and $\mathrm{Fe}$ (Figure S3) all exhibited strong linear relationships $\left(\mathrm{R}^{2}\right.$ values $\left.>0.96\right)$ across a wide range of mass loadings. The DGT/LA-ICPMS analysis was both sensitive and stable (Table S2). However, there were differences between elements, for example As sensitivity was $\sim 50$-fold higher than for Fe, but conversely the Fe measurement exhibited much lower signal variance (Table S2). The standard deviations (SDs) recorded in this study were similar to values calculated by Warnken et al. (2004) ${ }^{24}$ for a DGT LA-ICPMS method operating 
at a measurement resolution of $100 \mu \mathrm{m}$. The benefit of using a high-resolution analysis (100-200 $\mu \mathrm{m}$; Table S2) approach for solid-state sample quantification relates to the ability to generate a stable signal due to the high frequency of measurements, which is especially important when working with small sample areas.

The lack of matrix-matched calibration standards is widely recognized to be the biggest hindrance for accurate quantitative analysis of multi-elements by LA-ICPMS. ${ }^{39,40}$ If the samples and reference materials do not share the same basic characteristics (i.e. physical-chemical properties) LA-ICPMS can only be used as a semi-quantitative technique. ${ }^{36}$ The DGT/LA-ICPMS methods are not subject to these analysis shortcomings, with identical sample and standard matrix matching being easy to achieve. An additional benefit is that DGT gel analysis only requires a low laser energy, which is advantageous for measurement signal stability as well as the lifetime of the LA instrument. ${ }^{24}$

Performance evaluation of PF-DGT and PZ-DGT. Disparities in the measurement of As labile concentrations have been found between DGT samplers with different binding gel configurations. ${ }^{31}$ Here, testing of two DGT gel types within each individual PADDI probe deployment was made to verify that a consistent in situ value was achieved. ${ }^{\text {As }} C_{\text {DGT }}$ measured by PF-DGT was compared to the ${ }^{A s} C_{\text {DGT }}$ determined by neighboring PZ-DGTs $(\mathrm{n}=72)$ (Figure S4). Pearson correlation analysis showed that there was a significant positive relationship $(p<0.05)$ between PF-DGT and PZ-DGT measured ${ }^{A s} C_{\text {DGT }}$ with the coefficient being 0.76. A Mann-Whitney Test 
analysis also found there to be no significance difference in the measurement $(p=$ 0.098). However, despite the frequency distributions of PF-DGT and PZ-DGT measured ${ }^{\text {As }} C_{\text {DGT }}$ in the rhizosphere and anoxic bulk soil zones being shown to be closely associated (Figure S5), in the more reducing conditions of the plough pan (Table S3), there was a clear narrowing of the range of As measurements captured by the PF-DGT compared to that of PZ-DGT (Figure S5). A plausible explanation for this change is the loss of integrity of the PF-DGT, when exposed to low redox conditions, as the binding phase is susceptible to reductive dissolution, resulting in a loss of functionality. Hereafter, all DGT As measurements will refer to PZ-DGT.

\section{Spatial Heterogeneity at the Field Scale. Field Characterization. The selected} paddy was a typical field site in Jiangsu Province, China, which is one of the most productive and oldest rice cultivation areas in the World. Total concentrations of As, $\mathrm{Pb}$, and $\mathrm{Fe}$ in the topsoils $(0-15 \mathrm{~cm})$ at different sub-sites within the paddy field were approximately the same (Table S4). Whole field R.S.D's for $\mathrm{As}, \mathrm{Pb}$, and $\mathrm{Fe}$ concentrations were $7.5 \%, 4.7 \%$, and $2.2 \% \quad(n=27)$, respectively. The higher measurement variance observed for As may have been due to a slight elevation in the total contents at sample sub-sites 1-3, which were adjacent to a main road that bordered the test field. Two soil core samples $(0-25 \mathrm{~cm})$ were collected and sliced at $\sim 5 \mathrm{~cm}$ intervals to evaluate the element changes with depth (Table S5). There was no significant difference in the concentrations of As or Fe. However, for Pb there was a trend with the upper zones (rhizosphere and anoxic bulk soils) exhibiting a $\sim 30 \%$ 
higher concentration than the corresponding plough pan subsoils.

Regarding the physicochemical properties, the rhizosphere soil zone was found to have the highest TOC concentrations ( $\sim 4 \%)$. A gradual decline to $\sim 3 \%$ was witnessed thereafter with depth within the ploughed soil horizon $(0-15 \mathrm{~cm})$ (Table S5). Nevertheless, the TOC levels in subsoils $(15-25 \mathrm{~cm})$ were significantly lower, averaging less than half that measured in the upper zones. Changes in soil porosity mirrored that of TOC (Table S5), with the plough pan zone again found to be characteristically different to that of the upper soil layers. The soil $\mathrm{pH}$ trend ran inversely to TOC and porosity, with higher levels recorded in the plough pan compared to the upper zones (Table S5).

Bioavailability of Trace Inorganics. There was no significant difference detected in ${ }^{A s} C_{\text {DGT }}$ concentrations between the field's sampling sites (Lateral), yet there was a highly significant difference with soil depth (Vertical) (Table S6). No interaction term between the two spatial planes was observed. This is in keeping with the primary idea that fieldscale heterogeneity in rice paddies is influenced more by depth rather than being a lateral trend. Histograms of the frequency distributions of ${ }^{\mathrm{As}} \mathrm{CDGT}_{\mathrm{DG}}$ (Figure 3) further visualize this phenomenon, with each depth zone (rhizosphere, anoxic bulk, and plough pan) showing a unique distribution characteristics, distinguishing it from the other zones. A frequency distribution shows a summarized grouping of ${ }^{A s} C_{D G T}$ data divided into mutually exclusive classes and the number of occurrences in a class. However, patterns of ${ }^{A s} C_{\text {DGT }}$ for both the rhizosphere and anoxic bulk soils shared 
greater similarity to each other compared to the plough pan. In terms of mobilization intensity, the rhizosphere provided the greatest average flux, whereas release was lowest in the plough pan, i.e. a decreasing mobilization with depth (Figure 3). The importance of depth zonation as a driver of As mobilization heterogeneity featured strongly in the 3D fieldscale plots (Figure 4). Yet, a disconnection in the lateral heterogeneity between each of the three depth zones was also evidenced, i.e. the lateral position of hotspots between vertical soil layers was not synchronized.

In contrast to $\mathrm{As}, \mathrm{Pb}$ bioavailability varied significantly between lateral field positions but not with depth, indicating that the heterogeneity behaviors of $\mathrm{As}$ and $\mathrm{Pb}$ are quite distinct (Table S6). This is shown most clearly in Figure 3, where the three distribution peaks closely overlap. This convergence of bioavailability is of note because total concentrations of $\mathrm{Pb}$ in the soil varied significantly between the different vertical zones (Table S5). Similar to As though the lateral ${ }^{\mathrm{Pb}} \mathrm{CDGT}_{\text {DG }}$ maxima were not localized consistently within the three depth layers (Figure 4), indicative of a scattered/dispersed distribution across the paddy.

Fe and $S^{(-I I)}$ were both found to vary significantly in the lateral and vertical dimensions, in addition to possessing significant spatial interaction terms (Table S6). The frequency distributions of the two elements (Figure 3) differed substantially. For example, Fe bioavailability was centered on a relatively low labile concentration and featured regular hotspot maxima above the measure of central tendency. Meanwhile, for $\mathrm{S}^{(-\mathrm{II})}$, the opposite was observed. Here, few bioavailability hotspots were recorded, yet flux minima or element depletion zones were prevalent features (Figure 4). $\mathrm{S}^{(-\mathrm{II})}$ 
labile concentration trends with depth followed a consistent and expected pattern based on changing redox conditions (Figure 1A), with a greater average flux being

388 identified in the plough pan layer, while the rhizosphere delivered the lowest $\mathrm{S}^{(-\mathrm{II})}$ bioavailability. For $\mathrm{Fe}$ the bulk soil had a characteristically higher labile concentration than the rhizosphere topsoil layer, again in keeping with expected changes in the redox conditions in the soil profile, commensurate with enhanced

392 reductive dissolution of the Fe solid phase to $\mathrm{Fe}^{(\mathrm{II})}$ (Figure 1A). However, the average

${ }^{\mathrm{Fe}}$ CDGT values measured in the plough pan were markedly lower than other soil layers,

394 which could be indicative of iron-sulphide precipitation/formation. ${ }^{41}$ In the plough 395 pan zonation, there were some hotspots with maxima Fe labile concentrations and 396 minima $\mathrm{S}^{(-\mathrm{II})}$ labile concentrations, further supporting the interaction between Fe and 397 sulphide (Figure 4).

Sampling Strategies for Field Bioavailability Measurement. Field scale averages 400 of element bioavailability are needed for nutrient/risk assessment and land management, but become harder to obtain as site heterogeneity increases. This needs to be considered when optimizing sampling strategies in paddy rice soils. In designing 403 the sampling scheme for our PADDI probe method, we firstly based the protocol on 404 the principal of cluster sampling, because it is both economical and efficient. ${ }^{42}$ 405 However, field scale heterogeneity is a crucial factor when deciding on cluster 406 sampling number $(\mathrm{N})$, so for this we needed to collect in situ measurements from 407 which to calibrate our probe deployment. 

group of $\mathrm{N}$ clusters were randomly generated and the average ( $\left.\mathrm{X}_{\text {group }}\right)$ was calculated to compare with the average of the whole field $\left(\mathrm{X}_{\text {field }}\right)$. For example, if we set $\mathrm{N}$ as 3 , there will be $84\left(\mathrm{C}_{9}^{3}\right)$ different groups with each containing 3 clusters. Then the recovery, referring to the ratio of $\mathrm{X}_{\text {group }}$ (the average of group) to $\mathrm{X}_{\text {field }}$ (the average of the whole samples), was used to indicate the accuracy of the sampling methods. As expected, the range of recovery became narrower as cluster number increased. Regarding the release flux of ${ }^{\mathrm{As}} \mathrm{C}_{\mathrm{DGT}},{ }^{\mathrm{Fe}} \mathrm{C}_{\mathrm{DGT}}$, and ${ }^{\mathrm{Pb}} \mathrm{C}_{\mathrm{DGT}}$, the recovery of $\mathrm{X}_{\text {group }}$ was between $80-120 \%$ when the cluster number was higher than 6 . It signaled that the minimum number of clusters needed to reliably represent the whole field average should be $2 / 3$ of the total cluster number. However, for the plough pan ${ }^{\mathrm{Pb}} \mathrm{C}_{\mathrm{DGT}}$, the variation of the $\mathrm{Pb}$ flux was high and the recovery of $\mathrm{X}_{\text {group }}$ varied between $32 \%$ and $256 \%$ when $\mathrm{N}=1$ (Figure $\boldsymbol{S} 8(\boldsymbol{b})$ ). Only when $\mathrm{N}>8$ could the recovery of $\mathrm{X}_{\text {group }}$ meet target recovery ranges of $80-120 \%$. The greater heterogeneity predicted for ${ }^{\mathrm{Pb}} \mathrm{C}_{\mathrm{DGT}}$ is consistent with the frequency distribution data (Figure 3) and field mapping analysis (Figure 4), which suggests $\mathrm{Pb}$ mobilization is characteristically more localized and dispersed than the other elements in this studied field with a high frequency of hotspots.

Geochemical Regulation. Comparison of the ${ }^{\mathrm{As}} \mathrm{CDGT}_{\mathrm{DT}}$ and As in the soil porewaters reveals a number of quite different spatial trends (Figure S9). The most prominent 
being that increased bioavailability of As in the rhizosphere zone is not detected by

431 the porewater measurements, with the rhizosphere and anoxic bulk layers acting as

432 essentially one uniform soil-chemical unit. There is not only similar average

433 concentrations, but also highly significant correlations between the As porewater

434 concentrations in the rhizosphere and the bulk soil at the field scale. Furthermore, the

435 locations of porewater concentration maxima coincide within one another irrespective

436 of vertical zonation (Figure 4). The differences observed between ${ }^{A s}$ CDGT and As in

437 the porewaters indicate that the kinetics of resupply from soil particle phases make a

438 significant contribution to the ${ }^{\mathrm{As}} \mathrm{C}_{\mathrm{DGT}}$ values.

Higher ${ }^{A s} C_{\text {DGT }}$ levels in the rhizosphere compared to the anoxic bulk soil suggest

440 that the root biomass is playing a role in regulating As release at the field scale, and

441 this trend concurs with mobilization trends observed in a lake sediment which was

442 covered by submerged macrophytes. ${ }^{43}$ There are a number of mechanisms by which

443 roots enhance As release, for example, specialized functional molecules or enzyme

444 systems, such as acid phosphatases, produced by the roots can mobilize As species. ${ }^{44}$

445 The rhizospheric effect which relates to the improved accessibility of carbon to

446 microflora in the rooting zone also strongly influences the functional dynamics of

447 biotic catalyzed chemical change. ${ }^{41,45,46}$ Indeed, the decreasing trend of TOC with

448 increasing soil depth, which mirrors that of ${ }^{A s} C_{\text {DGT }}$ (Table 1), is supportive of

449 rhizophere-carbon being a controlling factor of release.

450 When developing a rapid/screening measurement system for in situ As

451 bioavailability, it could be argued that Fe mobilization patterns alone could be used as 
a proxy for As release, and there have been a number of studies that have shown that both porewater and DGT measurements of Fe and As in flooded soils/sediments, are significantly correlated/strongly associated both in the bulk environment ${ }^{47-51}$ and the apices of plant root tips ${ }^{8}$. Interestingly, correlations in this study between ${ }^{\text {As }} C_{\text {DGT }}$ and $\mathrm{S}^{(-\mathrm{II})}$ were highly significant (Table S7), but were not between ${ }^{\mathrm{As}} \mathrm{C}_{\mathrm{DGT}}$ and ${ }^{\mathrm{Fe}} \mathrm{CDGT}_{\text {DG }}$ However, similar disconnects between As and Fe, have been observed with DGT in paddy soils, tested in anaerobic conditions in the laboratory. ${ }^{27,52}$ This doesn't necessarily discount the importance of reductive dissolution of $\mathrm{Fe}$ in the $\mathrm{As}$ mobilization, but it does highlight that Fe bioavailability cannot be considered to represent that of As directly. There are a number of reasons for this, firstly secondary reactions such as precipitation of $\mathrm{Fe}$ in soil or re-adsorption of reduced $\mathrm{Fe}$ can occur. ${ }^{52}$ The coupled release of As and Fe could be very strong but it's masked by the differences in concentration, orders of magnitude higher, in the latter compared with the former. ${ }^{48}$ Alternatively, the differences could relate to the functional and phylogenetic diversity of the microorganisms controlling the As mobilization dynamics in different wetland/marine systems. ${ }^{45}$, 53 The inclusion of ${ }^{\mathrm{Mn}} \mathrm{CDGT}_{\mathrm{DG}}$ measurements, in paddies here could be an advantage, with Mn reduction occurring at neighboring/closely associated reducing conditions to that of Fe (Figure 1), but with slower rates of reoxidation, it could act as a better/more reliable redox marker within the PADDI set-up.

72 Regarding the bioavailability of $\mathrm{Pb}$ over the whole field, as expected, it showed a strong relationship with Fe (Table S7). This is exhibited most clearly in Figure 4, 

475 vertical depths. The high affinity between ${ }^{\mathrm{Pb}} \mathrm{CDGT}_{\mathrm{DG}}$ and ${ }^{\mathrm{Fe}} \mathrm{CDGT}_{\mathrm{DT}}$ revealed a similar 476 biogeochemical regulation processes for $\mathrm{Pb}$ and $\mathrm{Fe}$ mobilization. Their bioavailability 477 is controlled by a number of mechanisms integrating physicochemical conditions and

where the hotspots of $\mathrm{Fe}$ and $\mathrm{Pb}$ almost share the same lateral position at different microbial activity as well as the interaction between these two elements. Fe (hydr)oxide is an important reactive sorption surface for $\mathrm{Pb}$ and the dissolution of $\mathrm{Fe}$ (hydr)oxide can lead to a concurrent release of $\mathrm{Pb}{ }^{54,}{ }^{55}$ Also, both $\mathrm{Fe}$ and $\mathrm{Pb}$ mobilization are sensitive to $\mathrm{pH}$ which was much lower in the ploughed vertical zones, leading to higher $\mathrm{Fe}$ and $\mathrm{Pb}$ labile concentrations. It was of note that there was a significant relationship between ${ }^{\mathrm{Fe}} \mathrm{C}_{\mathrm{DGT}}$ and $\mathrm{S}^{(-\mathrm{II})}$ labile concentrations (Pearson correlation, $p<0.05$ ), with a contrasting trend with vertical depth (Table 1). Sulfide precipitation is the predominant abiotic mechanism of Fe transformation in the soil where sulfate-reducing conditions have been established. Meanwhile sulfate-reducing bacteria, via a direct enzymatic pathway, also reduce $\mathrm{Fe}^{(\mathrm{III})}{ }^{56}$ Therefore, sulfate-sulfide cycling is an important regulator of a variety of sulfur-driven biogeochemical cycling events, influencing the bioavailability of various metal(loid)s.

Environmental Implications. Rice is one of three main global crops, occupying over 140 million hectares worldwide. ${ }^{57}$ The dimensions of the paddy soil environment (topsoil-plough pan) can be compared to those of a "thin-film", i.e. shallow depth but much more extensive surface area. However, the elemental release characteristics of this "thin-film" environment at resolutions $>10 \mathrm{~m}^{2}$ are poorly understood. In this study, 
for the first time, the heterogeneity of dynamic element bioavailability at the field scale was quantitatively measured using the DGT technique and a novel probe assembly, designed specifically for paddy field deployment. Findings from this work highlight that the heterogeneity patterns of element bioavailability in agricultural wetland soils differ between the horizontal and vertical planes, with there being greater change across shorter distances in the latter. One of the main reasons for this relates to the complexity of the elemental regulation of bioavailability.

To understand this, four sampling requirements must be met. Measurements need to be in situ, multi-elemental, of appropriate deployment scale and dynamic. Currently, there are a lack of methods that meet all four of these criteria. However, the DGT-PADDI probe is one of the few techniques that does comply to these rules, offering a superior measurement of trace element bioavailability at the field scale. The probe configuration selected in this study was devized to assess a number of performance criteria, including quality control, reliability, and consistency. By simply loading alternative sampler gels into the probe, the suite of elemental measurements collected can be increased. Adaptations of the DGT-PADDI to both accommodate Fe/As species and DOC capture, would enhance our understanding of the element mobilization processes in riceland soils. However, a limitation of a purely chemical approach is the failure to isolate soil microflora function. The DGT-PADDI probe as a method platform has the potential, with a little further modification, to collect both taxonomic domain and targeted gene-based data, alongside DGT derived kinetics and soil solution measurements, and thereby directly link chemical observations to 
biological processes.

\section{a ASSOCIATED CONTENT}

\section{Supporting Information}

Description of the methodology summary for high-resolution 2D imaging of the rice soil environment using DGT probe (Text S1), Standard calibrations for DGT gels (Text S2), soil sampling for field characterization (Text S3), determination of soil physicochemical properties (Text S4), relevant information on DGT theory and its principal to determine the bioavailable concentration of elements (Text S5), instrumental parameters for LA-ICP-MS analysis (Table S1), LOD, SD, and resolution of LA-ICP-MS analysis of gel standards (Table S2), physicochemical properties of soils (Table S3-S5), analysis of variance of sampling sites and vertical zones on $C_{\text {DGT }}$ of $\mathrm{As}, \mathrm{Pb}, \mathrm{Fe}$, and $\mathrm{S}^{(-\mathrm{II})}$ (Table $\mathrm{S} 6$ ), Pearson correlations among $\mathrm{As}, \mathrm{Pb}$, Fe fluxes and $\mathrm{S}^{(-\mathrm{II})}$ gray-scale value based on PADDI measurement (Table S7), weather information of the sampling site (Table S8), the components of DGT device and its principal to measure labile concentration (Figure S1), calibration curves of As, $\mathrm{Pb}$, and $\mathrm{Fe}$ for quantitative LA-ICP-MS analysis (Figure S2), data processing for LA-ICP-MS results of gel standards and sample gels (Figure S3), relationship between ${ }^{\mathrm{As}} \mathrm{C}_{\mathrm{DGT}}$ measured by PZ-DGT and PF-DGT (Figure S4), frequency distributions of 72 replicates for ${ }^{A s} C_{D G T}$ measured by PZ and PF binding gels at the whole field scale (Figure S5), the change of recovery of the mean (a) ${ }^{\mathrm{Fe}} \mathrm{C}_{\mathrm{DGT}}$, (b) ${ }^{\mathrm{Pb}} \mathrm{C}_{\mathrm{DGT}}$, and (c) ${ }^{\mathrm{As}} \mathrm{C}_{\mathrm{DGT}}$ at the different soil zonations with cluster sampling number 
540 (Figure S6-S8), and field scale heterogeneity in pore-water relative concentrations of

$541 \mathrm{As}, \mathrm{Fe}$, and $\mathrm{Pb}$ (Figure S9). This material is available free of charge via the Internet at

542 http://pubs.acs.org.

- AUTHOR INFORMATION

\section{Corresponding Author}

*Phone: 0086-25-89680632 (J. Luo). E-mail: esluojun@nju.edu.cn (J. Luo);

p.williams@qub.ac.uk (P. N. Williams). Phone: 0044-28-9077-6539

\section{- ACKNOWLEDGEMENTS}

549 This work was funded by the National Natural Science Foundation of China (No.

550 41771271), the Fundamental Research Funds for the Central Universities (021114380063), and the Chinese Academy of Sciences' (CAS) President's International Fellowship Initiative (PIFI) award (2016VEC001). The study also received support from the Newton Fund/Royal Society and NFSC (R1504GFS and 21511130063).

\section{- REFERENCES}

(1) Søvik, M. L.; Larssen, T.; Vogt, R. D.; Wibetoe, G.; Feng, X. Potentially harmful elements in rice paddy fields in mercury hot spots in Guizhou, China. Appl. Geochemistry 2011, 26, 167-173.

(2) Zhao, F. J.; Ma, Y. B.; Zhu, Y. G.; Tang, Z.; McGrath, S. P. Soil contamination in China: Current status and mitigation strategies. Environ. Sci. Technol. 2015, 49, 750-759.

(3) Fu, J.; Zhang, A.; Wang, T.; Qu, G.; Shao, J.; Yuan, B.; Jiang, G. Influence of e-waste dismantling and its regulations: temporal trend, spatial distribution of heavy metals in rice grains, and its potential health risk. Environ. Sci. 
(4) Seyfferth, A.L.; McCurdy, S.; Schaefer, M.V.; Fendorf, S. Arsenic concentrations in paddy soil and rice and health implications for major rice growing regions of Cambodia. Environ. Sci. Technol. 2014, 48, 4699 - 4706.

(5) Stone, R. Arsenic and paddy rice: a neglected cancer risk? Science. 2008, 321 (5886), 184-185.

(6) Zhao, F. J.; Zhu, Y. G., Meharg, A. A. Methylated arsenic species in rice: Geographical variation, origin, and uptake mechanisms. Environ. Sci. Technol. 2013 47, 3957-3966.

(7) Khaokaew, S.; Chaney, R. L.; Landrot, G.; Ginder-Vogel, M.; Sparks, D. L. Speciation and Release Kinetics of Cadmium in an Alkaline Paddy Soil under Various Flooding Periods and Draining Conditions. Environ. Sci. Technol. 2011, 45 (10), 4249-4255.

(8) Williams, P. N.; Santner, J.; Larsen, M.; Lehto, N. J.; Oburger, E.; Wenzel, W.; Glud, R. N.; Davison, W.; Zhang, H. Localized Flux Maxima of Arsenic, Lead, and Iron around Root Apices in Flooded Lowland Rice. Environ. Sci. Technol. 2014, 48 (15), 8498-8506.

(9) Khaokaew, S.; Landrot, G.; Chaney, R. L.; Pandya, K.; Sparks, D. L. Speciation and Release Kinetics of Zinc in Contaminated Paddy Soils. Environ. Sci. Technol. 2012, 46 (7), 3957-3963.

(10) Somenahally, A. C.; Hollister, E. B.; Yan, W.; Gentry, T. J.; Loeppert, R. H. Water Management Impacts on Arsenic Speciation and Iron-Reducing Bacteria in Contrasting Rice-Rhizosphere Compartments. Environ. Sci. Technol. 2011, 45 (19), 8328-8335.

(11) Kuzyakov, Y., \& Blagodatskaya, E. Microbial hotspots and hot moments in soil: concept \& review. Soil Biol. Biochem. 2015, 83, 184-199.

(12) EPA. Soil Screening Guidance: Technical Background Document. EPA/540/R95/128. 1996, US Environmental Protection Agency, Office of Solid Waste and Emergency Response.

(13) Davison, W. Diffusive Gradients in Thin-Films for Environmental Measurements. Cambridge University Press: 2016.

(14) Davison, W.; Zhang, H. In situspeciation measurements of trace components in natural waters using thin-film gels. Nature. 1994, 367 (6463), 546-548. 
(15) Zhang, H.; Davison, W. Direct in situ measurements of labile inorganic and organically bound metal species in synthetic solutions and natural waters using diffusive gradients in thin films. Anal. Chem. 2000, 72 (18), 4447-4457.

(16) Guan, D.; Williams, P. N.; Luo, J.; Zheng, J.; Xu, H.; Cai, C.; Ma, L. Q. Novel Precipitated Zirconia-Based DGT Technique for High-Resolution Imaging of Oxyanions in Waters and Sediments. Environ. Sci. Technol. 2015, 49 (6), 3653-3661.

(17) Glæsner, N.; Donner, E.; Magid, J.; Rubæk, G. H.; Zhang, H.; Lombi, E. Characterization of Leached Phosphorus from Soil, Manure, and Manure-Amended Soil by Physical and Chemical Fractionation and Diffusive Gradients in Thin Films (DGT). Environ. Sci. Technol. 2012, 46 (19), 10564-10571.

(18) Luo, J.; Zhang, H.; Davison, W.; McLaren, R. G.; Clucas, L. M.; Ma, L. Q.; Wang, X. Localised mobilisation of metals, as measured by diffusive gradients in thin-films, in soil historically treated with sewage sludge. Chemosphere. 2013, 90 (2), 464-470.

(19) Eismann, C. E.; Menegário, A. A.; Gemeiner, H.; Williams, P. N. Predicting Trace Metal Exposure in Aquatic Ecosystems: Evaluating DGT as a Biomonitoring Tool. Expos. Health. 2018, 1-13.

(20) Ndu, U.; Christensen, G. A.; Rivera, N. A.; Gionfriddo, C. M.; Deshusses, M. A.; Elias, D. A.; Hsu-Kim, H. Quantification of Mercury Bioavailability for Methylation Using Diffusive Gradient in Thin-Film Samplers. Environ. Sci. Technol. 2018. DOI: $10.1021 /$ acs.est. 8 b00647

(21) Kreuzeder, A.; Santner, J.; Zhang, H.; Prohaska, T.; Wenzel, W. W. Uncertainty evaluation of the diffusive gradients in thin films technique. Environ. Sci. Technol. 2015, 49, 1594-602.

(22) Santner, J.; Larsen, M.; Kreuzeder, A.; Glud, R. N. Two decades of chemical imaging of solutes in sediments and soils - a review. Anal. Chim. Acta. 2015, $878,9-42$.

(23) Stockdale, A.; Davison, W.; Zhang, H. High-resolution two-dimensional quantitative analysis of phosphorus, vanadium and arsenic, and qualitative analysis of sulfide, in a freshwater sediment. Environ. Chem. 2008, 5 (2), 143-149.

(24) Warnken, K. W.; Zhang, H.; Davison, W. Analysis of polyacrylamide gels for 
trace metals using diffusive gradients in thin films and laser ablation inductively coupled plasma mass spectrometry. Anal. Chem. 2004, 76 (20), 6077-6084.

(25) Alexa, N.; Zhang, H.; Lead, J. R. Development of a miniaturized diffusive gradients in thin films (DGT) device. Anal. Chim. Acta. 2009, 655 (1), 80-85.

(26) Guan, D.; Williams, P. N.; Xu, H.; Li, G.; Luo, J.; Ma, L. Q. High-resolution measurement and mapping of tungstate in waters, soils and sediments using the low-disturbance DGT sampling technique. J. Hazard. Mater. 2016, 316, 69-76.

(27) Williams, P. N.; Zhang, H.; Davison, W.; Meharg, A. A.; Hossain, M.; Norton, G. J.; Brammer, H.; Islam, M. R., Organic Matter-Solid Phase Interactions Are Critical for Predicting Arsenic Release and Plant Uptake in Bangladesh Paddy Soils. Environ. Sci. Technol. 2011, 45 (14), 6080-6087.

(28) Kirk, G. The Biogeochemistry of Submerged Soils. Chichester, UK: John Wiley: 2004.

(29) Robertson, D.; Welsh, D. T.; Teasdale, P. R. Investigating biogenic heterogeneity in coastal sediments with two-dimensional measurements of iron(II) and sulfide. Environ. Chem. 2009, 6, 60.

(30) Luo, J.; Zhang, H.; Santner, J.; Davison, W. Performance characteristics of diffusive gradients in thin films equipped with a binding gel layer containing precipitated ferrihydrite for measuring arsenic (V), selenium (VI), vanadium (V), and antimony (V). Anal. Chem. 2010, 82 (21), 8903-8909.

(31) Garnier, J. M.; Garnier, J.; Jézéquel, D.; Angeletti, B. Using DET and DGT probes (ferrihydrite and titanium dioxide) to investigate arsenic concentrations in soil porewater of an arsenic-contaminated paddy field in Bangladesh. Sci. Total. Environ. 2015, 536, 306-315.

(32) Warnken, K. W.; Zhang, H.; Davison, W. Performance characteristics of suspended particulate reagent-iminodiacetate as a binding agent for diffusive gradients in thin films. Anal. Chim. Acta. 2004, 508 (1), 41-51.

(33) Teasdale, P. R.; Hayward, S.; Davison, W. In situ, high-resolution measurement of dissolved sulfide using diffusive gradients in thin films with computer-imaging densitometry. Anal. Chem. 1999, 71 (11), 2186-2191.

(34) Davison, W.; Zhang, H.; Grime, G. W. Performance characteristics of gel probes used for measuring the chemistry of pore waters. Environ. Sci. Technol. 
(35) Gao, Y.; Lehto, N. A simple laser ablatin ICP-MS method for the determination of trace metals in a resin gel. Talanta. 2012, 92, 78-83.

(36) Santner, J.; Prohaska, T.; Luo, J.; Zhang, H. Ferrihydrite Containing Gel for Chemical Imaging of Labile Phosphate Species in Sediments and Soils Using Diffusive Gradients in Thin Films. Anal. Chem. 2010, 82 (18), 7668-7674.

(37) Lin, J.; Liu, Y.; Yang, Y.; Hu, Z. Calibration and correction of LA-ICP-MS and LA-MC-ICP-MS analyses for element contents and isotopic ratios. Solid Earth Sci. 2016, 1 (1), 5-27.

(38) Robertson, D.; Teasdale, P.R.; Welsh, D.T. A novel gel-based technique for the high resolution, two-determination of iron (II) and sulfide in sediment. Limnol. Oceangr. Meth. 2008, 6(10), 502-512.

(39) Durrant, S. F.; Ward, N. I. Recent biological and environmental applications of laser ablation inductively coupled plasma mass spectrometry (LA-ICP-MS). $J$. Anal. Atom. Spectrom. 2005, 20 (9), 821-829.

(40) Miliszkiewicz, N.; Walas, S.; Tobiasz, A. Current approaches to calibration in LA-ICP-MS analysis. J. Anal. Atom. Spectrom. 2015, 30 (2), 327-338.

(41) Bao, P.; Li, G.; Sun, G.; Xu, Y.; Meharg, A. A.; Zhu, Y. The role of sulfate-reducing prokaryotes in the coupling of element biogeochemical cycling. Sci. Total. Environ. 2018, 613, 398-408.

(42) Webster R.; Lark R. M. Field sampling for environmental science and management. London: Earthscan, 2013.

(43) Sun, Q.; Ding, S.; Wang, Y.; Xu, L.; Wang, D.; Chen, J.; Zhang, C. In-situ characterization and assessment of arsenic mobility in lake sediments. Environ. Pollut. 2016, 214, 314-323.

(44) Brennan, A.; Jiménez, E. M.; Puschenreiter, M.; Alburquerque, J. A.; Switzer, C. Effects of biochar amendment on root traits and contaminant availability of maize plants in a copper and arsenic impacted soil. Plant Soil 2014, 379 (1-2), 351-360.

(45) Zhang, S.; Williams, P. N.; Luo, J.; Zhu, Y. Microbial mediated arsenic biotransformation in wetlands. Front. Env. Sci. Eng. 2017, 11 (1), 1-11.

(46) Fendorf, S.; Michael, H. A.; van Geen, A. Spatial and temporal variations of 
groundwater arsenic in South and Southeast Asia. Science 2010, 328 (5982), 1123-1127.

(47) Gao, Y.; Lesven, L.; Gillan, D.; Sabbe, K.; Billon, G.; De Galan, S.; Elskens, M.; Baeyens, W.; Leermakers, M. Geochemical behavior of trace elements in sub-tidal marine sediments of the Belgian coast. Mar. Chem. 2009, 117, 88-96.

(48) Zhang, H.; Davison, W.; Mortimer, R. J. G.; Krom, M. D.; Hayes, P. J.; Davies, I. M. Localized remobilization of metals in a marine sediment. Sci. Total Environ. 2002, 296, 175-187.

(49) Garnier, J. M.; Hurel, C.; Garnier, J.; Lenoble, V.; Garnier, C.; Ahmed, K. M.; Rose, J. Strong chemical evidence for high Fe(II)-colloids and low As-bearing colloids $(200 \mathrm{~nm}-10 \mathrm{kDa})$ contents in groundwater and flooded paddy fields in Bangladesh: A size fractionation approach. Appl. Geochemistry. 2011, 26, 1665-1672.

(50) Bennett, W. W.; Teasdale, P. R.; Panther, J. G.; Welsh, D. T.; Zhao, H.; Jolley, D. F. Investigating arsenic speciation and mobilization in sediments with DGT and DET: a mesocosm evaluation of oxic-anoxic transitions. Environ. Sci. Technol. 2012, 46, 3981-3989.

(51) Hossain, M.; Williams, P. N.; Mestrot, A.; Norton, G. J.; Deacon, C. M.; Meharg, A. A. Spatial heterogeneity and kinetic regulation of arsenic dynamics in mangrove sediments: the Sundarbans, Bangladesh. Environ. Sci. Technol. 2012, 46 (16), 8645-8652.

(52) Chowdhury, M. T. A.; Deacon, C. M.; Steel, E.; Imamul Huq, S. M.; Paton, G. I.; Price, A. H.; Williams, P. N.; Meharg, A. A.; Norton, G. J. Physiographical variability in arsenic dynamics in Bangladeshi soils. Sci. Total. Environ. 2018, 612, 1365-1372.

(53) Reid, M. C.; Maillard, J.; Bagnoud, A.; Falquet, L.; Le Vo, P.; Bernier-Latmani, R. Arsenic Methylation Dynamics in a Rice Paddy Soil Anaerobic Enrichment Culture. Environ. Sci. Technol. 2017, 51, 10546-10554.

(54) Fang W.; Wei Y.; Liu J. Comparative characterization of sewage sludge compost and soil: Heavy metal leaching characteristics. J. Hazard. Mater. 2016, 310, 1-10.

(55) Fang, W.; Delapp, R. C.; Kosson, D. S.; Van der Sloot, H. A.; Liu, J. Release of heavy metals during long-term land application of sewage sludge compost: Percolation leaching tests with repeated additions of compost. Chemosphere. 2017, 169, 271-280. 
(56) Coleman, M. L.; Hedrick, D. B.; Lovley, D. R.; White, D. C.; Pye, K. Reduction of Fe(III) in sediments by sulphate-reducing bacteria. Nature. 1993, 361 (6411), $436-438$.

(57) Database of Food and Agriculture Organization of the United Nations, 2017.

796

797 


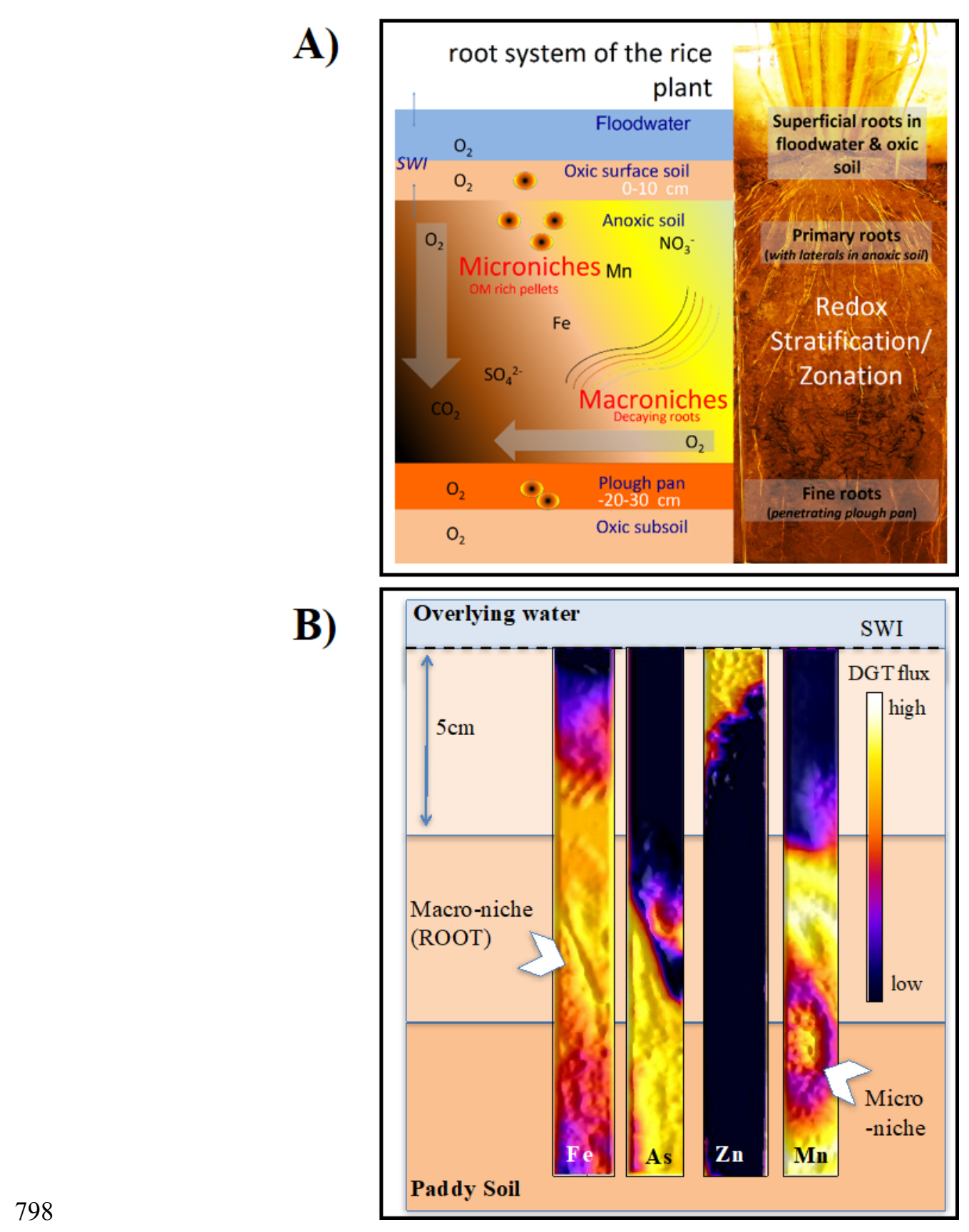

799 Figure 1. Trace element bioavailability within rice paddy soils. A) Visualization of

800 the primary drivers of heterogeneity in trace inorganic mobilisation. B) 801 High-resolution 2D imaging of the rice soil environment using DGT (see 802 Supplementary Text 1 for a summary of the methodology). 


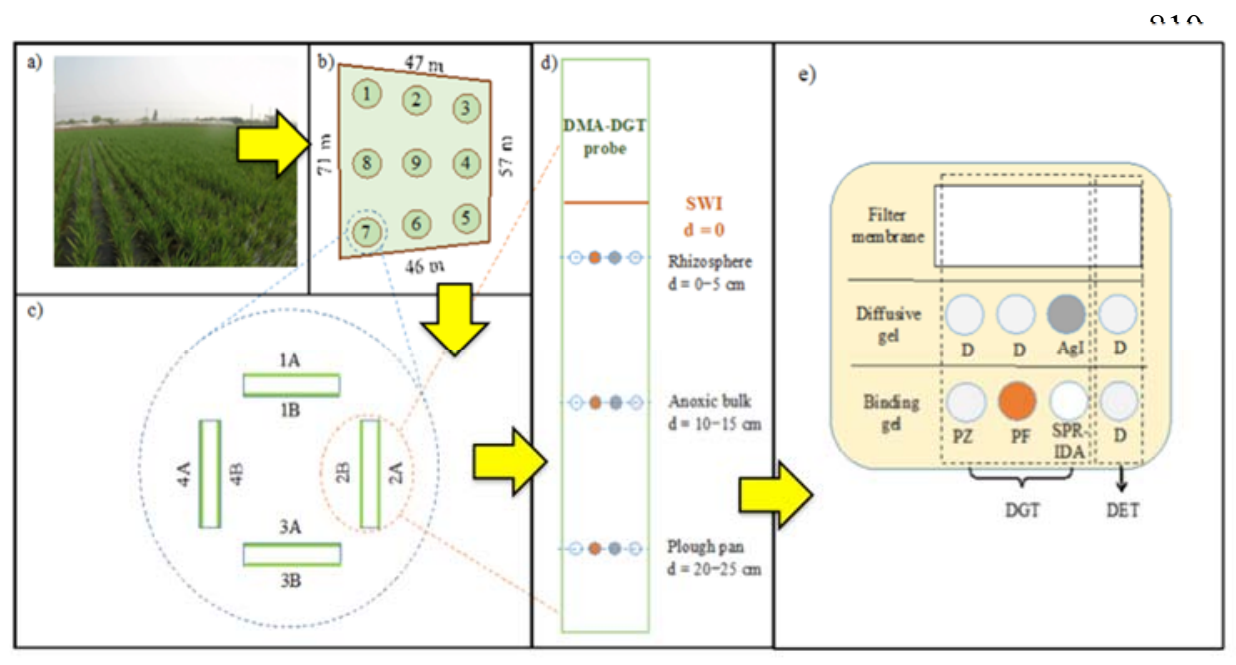

820 Figure 2. In-situ deployment of PADDI probes in a paddy field. a) Aerial photograph 821 of field site, b) schematic of sample site, c) probe deployment configuration - plan view, d) probe layout, e) Structure and assembly of the PADDI probe. Precipitated ferrihydrite binding gel (PF)-diffusive gel (PF-DGT) and precipitated zirconia binding gel (PZ)- diffusive gel (PZ-DGT) for measuring As DGT flux, suspended particulate reagent-iminodiacetate binding gel (SPR-IDA)-AgI embedded diffusive gel (SPR-IDA-AgI-DGT) for measuring $\mathrm{Pb}$ and $\mathrm{Fe}$ DGT fluxes and $\mathrm{S}^{(-\mathrm{II})}$ content, and a diffusive gel- diffusive gel (DET) for simultaneously measuring $\mathrm{As}, \mathrm{Pb}$, and $\mathrm{Fe}$ concentrations in pore-water. 

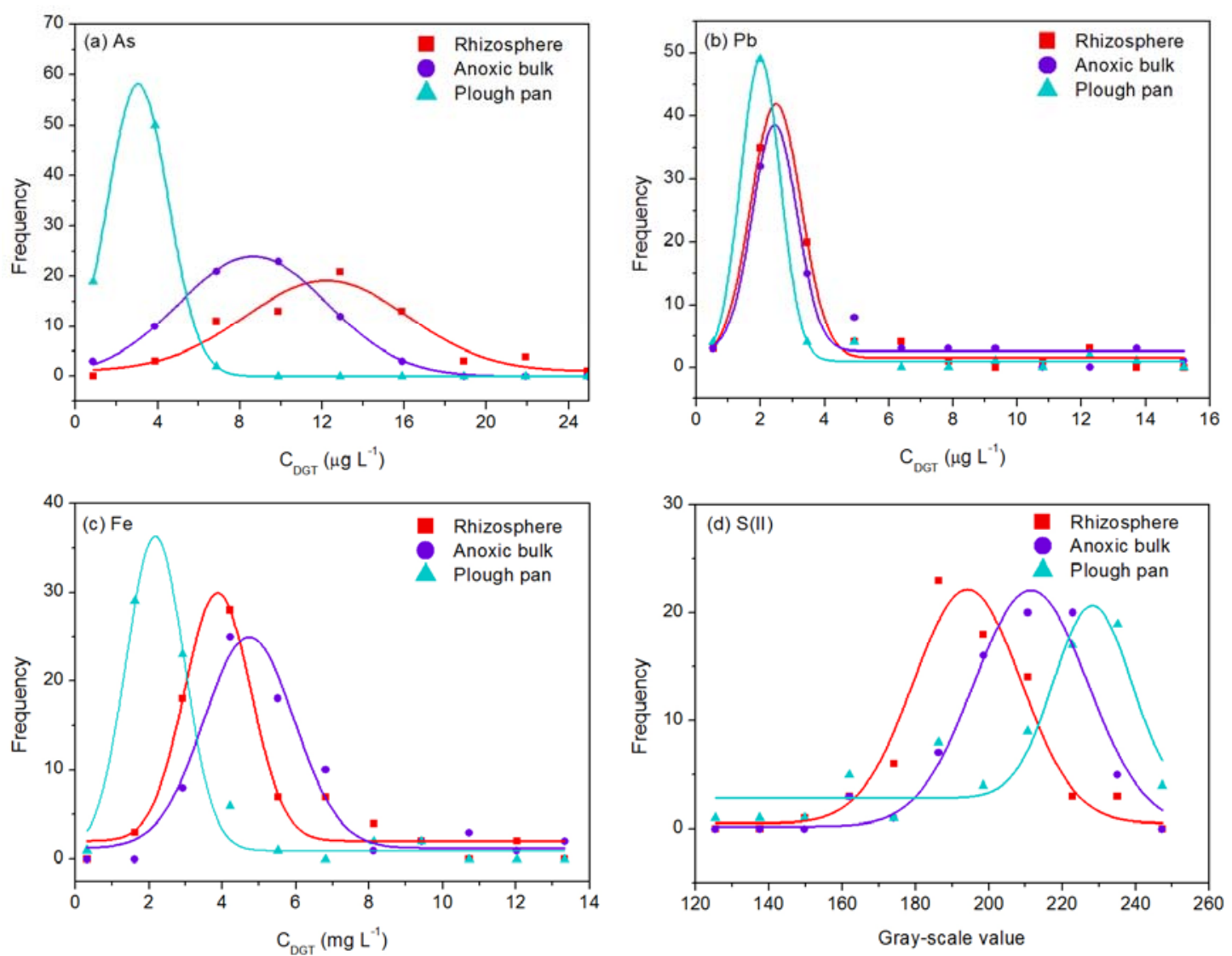

Figure 3. Field scale heterogeneity in the bioavailability of trace inorganics: Part I.

Frequency distributions of 72 replicates for PADDI probe measured $\mathrm{C}_{\mathrm{DGT}}$ of $\mathrm{As}, \mathrm{Pb}$, $\mathrm{Fe}$ and gray-scale value of $\mathrm{S}^{(-\mathrm{II})}$ at the whole field scale. 
(a) As

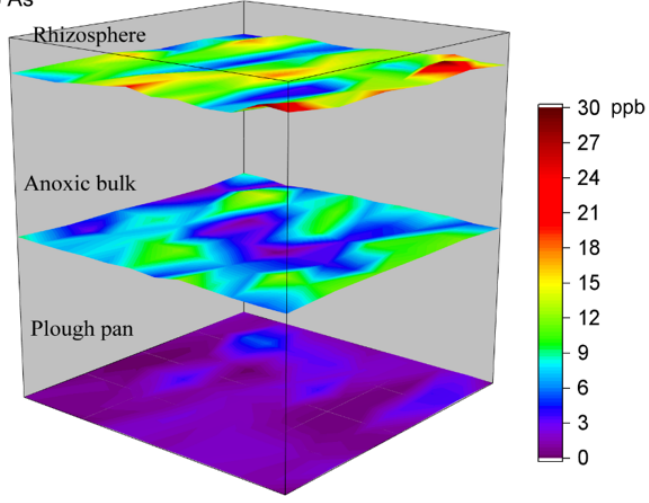

(c) $\mathrm{Fe}$

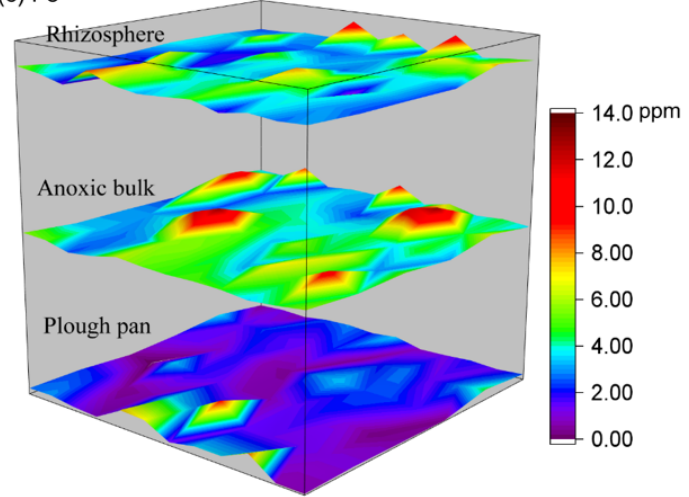

(b) $\mathrm{Pb}$

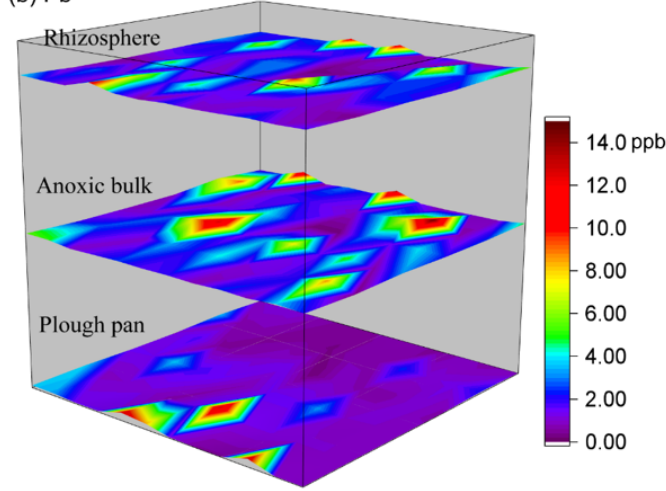

(d) S(II) Gray-scale values

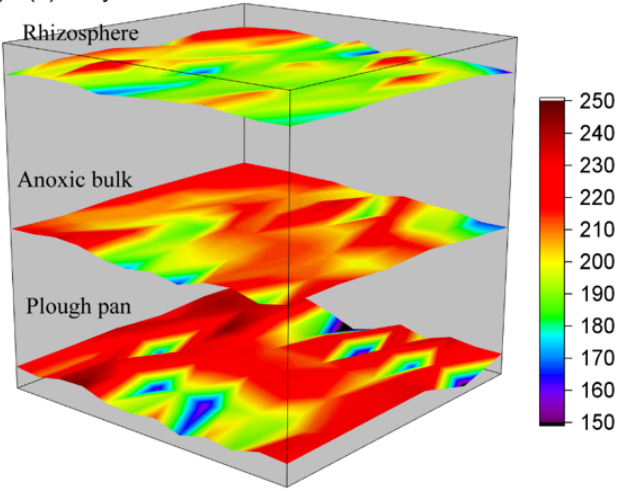

Figure 4. Field scale heterogeneity in the bioavailability of trace inorganics: Part II. A whole field-3D-overview of the bioavailability for (a) ${ }^{\mathrm{As}} \mathrm{DGT}$, (b) ${ }^{\mathrm{Fe}} \mathrm{DGT}$, (c) ${ }^{\mathrm{Pb}} \mathrm{DGT}$, and (d) $\mathrm{S}^{(-\mathrm{II})}$ Gray-scale value. 
840 Table 1. $\boldsymbol{C}_{\text {DGT }}$ of $\mathrm{As}, \mathrm{Pb}$, and Fe and gray-scale value of $\mathrm{S}^{(-\mathrm{II})}$ measured by $\mathrm{PADDI}$

841 probes in three vertical soil zones.

\begin{tabular}{cccccccc}
\hline Soil zones & $\begin{array}{c}\mathrm{As} \\
\left(\mu \mathrm{g} \mathrm{L}^{-1}\right)\end{array}$ & $\begin{array}{c}\mathrm{Pb} \\
\left(\mu \mathrm{g} \mathrm{L}^{-1}\right)\end{array}$ & $\begin{array}{c}\mathrm{Fe} \\
\left(\mathrm{mg} \mathrm{L}^{-1}\right)\end{array}$ & $\begin{array}{c}\text { Gray-scale } \\
\text { values }\end{array}$ & porosity & TOC & $\mathrm{pH}$ \\
\hline $\begin{array}{c}\text { Rhizosphere } \\
(0-5 \mathrm{~cm})\end{array}$ & $11.62 \pm 5.52$ & $2.63 \pm 2.50$ & $4.10 \pm 2.13$ & $195 \pm 16$ & 0.58 & $4.09 \pm 0.13$ & 5.54 \\
$\begin{array}{c}\text { Anoxic bulk } \\
(10-15 \mathrm{~cm})\end{array}$ & $7.15 \pm 3.28$ & $3.22 \pm 3.26$ & $4.99 \pm 2.46$ & $208 \pm 16$ & 0.46 & $3.08 \pm 0.01$ & 5.79 \\
$\begin{array}{c}\text { Plough pan } \\
(20-25 \mathrm{~cm})\end{array}$ & $1.58 \pm 1.12$ & $1.86 \pm 2.53$ & $2.18 \pm 1.84$ & $212 \pm 27$ & 0.37 & $1.46 \pm 0.10$ & 6.80 \\
\hline
\end{tabular}

842 